\section{Subclinical Atherosclerosis in Ankylosing Spondylitis}

\section{To the Editor:}

An issue of growing interest in the management of patients with chronic inflammatory rheumatic diseases is the identification of high-risk individuals who may benefit from active therapy to prevent the development of cardiovascular events. Ultrasound techniques based on flow velocity and intima thickness offer a unique opportunity to study the relation of surrogate markers to the development of atherosclerosis. Recently, Bodnár, et al assessed 40 patients with ankylosing spondylitis (AS) and confirmed the presence of subclinical atherosclerosis in them ${ }^{1}$. These results are in agreement with observations of our group that disclosed the presence of endothelial dysfunction and abnormally increased values of common carotid intima-media wall thickness (IMT) in patients with psoriatic arthritis (PsA), another disease included within the spondyloarthropathies ${ }^{2,3}$. Of note, our studies included a previously selected group of PsA patients without clinically evident cardiovascular disease and absence of classic cardiovascular risk factors ${ }^{2,3}$.

We also note the extremely interesting data reported by Bodnár, et $a l^{1}$ showing increased common carotid IMT in patients with AS. In this regard, using high-resolution B-mode ultrasound in 64 patients with AS and 64 matched controls, we observed that carotid plaques were more common in patients with AS $[19(29.7 \%) \text { ] than in controls [6 (9.4\%); } \mathrm{p}=0.03]^{4}$. However, although in the elegant study by Bodnár, et al it is said that in our series the common carotid IMT was unchanged, we also observed that AS patients exhibited greater carotid IMT than matched controls (mean $0.74 \pm$ $0.21 \mathrm{~mm}$ vs $0.67 \pm 0.14 \mathrm{~mm} ; \mathrm{p}=0.01$; differences of means: $0.077,95 \%$ CI $0.016-0.139)^{4}$.

Considering all this evidence, along with recent observation of the potential value of carotid ultrasonography as a predictor of cardiovascular events in patients with rheumatoid arthritis ${ }^{5}$, we support the potential use of carotid ultrasonography to establish a subgroup of patients with chronic inflammatory rheumatic diseases and high risk of cardiovascular complications.
MIGUEL A. GONZALEZ-GAY, MD, PhD, Rheumatology Division, Hospital Universitario Marques de Valdecilla, IFIMAV, Santander; CARLOS GONZALEZ-JUANATEY, MD, PhD, Cardiology Division, Hospital Xeral-Calde, Lugo; JAVIER LLORCA, MD, PhD, Division of Preventive Medicine and Public Health, School of Medicine, University of Cantabria, IFIMAV, Santander, Spain. Address correspondence to Dr. Gonzalez-Gay: E-mail: miguelaggay@hotmail.com

\section{REFERENCES}

1. Bodnár N, Kerekes G, Seres I, Paragh G, Kappelmayer J, Némethné ZG, et al. Assessment of subclinical vascular disease associated with ankylosing spondylitis. J Rheumatol 2011; 38:723-9.

2. Gonzalez-Juanatey C, Llorca J, Miranda-Filloy JA, Amigo-Diaz E, Testa A, Garcia-Porrua C, et al. Endothelial dysfunction in psoriatic arthritis patients without clinically evident cardiovascular disease or classic atherosclerosis risk factors. Arthritis Rheum 2007;57:287-93.

3. Gonzalez-Juanatey C, Llorca J, Amigo-Diaz E, Dierssen T, Martin J, Gonzalez-Gay MA. High prevalence of subclinical atherosclerosis in psoriatic arthritis patients without clinically evident cardiovascular disease or classic atherosclerosis risk factors. Arthritis Rheum 2007;57:1074-80.

4. Gonzalez-Juanatey C, Vazquez-Rodriguez TR, Miranda-Filloy JA, Dierssen T, Vaqueiro I, Blanco R, et al. The high prevalence of subclinical atherosclerosis in patients with ankylosing spondylitis without clinically evident cardiovascular disease. Medicine 2009;88:358-65.

5. Gonzalez-Juanatey C, Llorca J, Martin J, Gonzalez-Gay MA Carotid intima-media thickness predicts the development of cardiovascular events in patients with rheumatoid arthritis. Semin Arthritis Rheum 2009;38:366-71.

J Rheumatol 2011;38:9; doi:10.3899/jrheum.110335 